\title{
LEVANTAMENTO FLORÍSTICO DAS ESPÉCIES UTILIZADAS NA ARBORIZAÇÃO DE PRAÇAS NO MUNICÍPIO DE NOVA XAVANTINA - MT
}

\author{
FLORISTIC SURVEY OF SPECIES USED IN SQUARES AFFORESTATION IN THE \\ MUNICIPALITY OF NOVA XAVANTINA - MT
}

Jesiane Pinele de Lima1; Carlos Kreutz²; Oriales Rocha Pereira ${ }^{3}$

\section{RESUMO}

A cidade de Nova Xavantina - MT possui diversas praças compondo o seu espaço de área verde. $O$ conhecimento do tipo de vegetação que compõe a arborização destas praças é importante para melhorar a qualidade ambiental ou direcionar ações que visem adequar o planejamento e manejo paisagístico. $O$ trabalho teve como objetivos: i) fazer o levantamento da composição florística das praças públicas situadas no município; ii) identificar a origem dessas espécies, se nativas ou exóticas; e iii) verificar se há similaridade na composição florística entre essas praças. Este trabalho teve como área de estudo as 12 praças do município. A identificação florística ocorreu por meio de visitas às praças, com identificação in situ e consulta ao Herbário NX. Foram encontrados 851 indivíduos, distribuídos em 86 espécies e 28 famílias. As famílias que apresentaram maior riqueza de espécies foram Fabaceae (20 espécies), Arecaceae (12) e Bignoniaceae (10). A maioria das famílias registrou de uma a três espécies apenas. Do total de espécies encontradas, $55 \%$ são nativas. A similaridade florística entre as praças do município é baixa, pois apenas três grupos apresentaram alta similaridade, evidenciando assim que uma maior diversidade de espécies está sendo utilizada na arborização das praças do município.

Palavras-chave: Áreas verdes; Qualidade de vida; Riqueza de espécies.

\section{ABSTRACT}

The municipality of Nova Xavantina - MT has several squares composing its space green area. Knowledge of the type of vegetation that composes the afforestation of these squares is important to improve the environmental quality or direct actions aimed at adapting the planning and management of this landscape afforestation. The study aimed to: i) make an inventory of the floristic composition of the public squares in the municipality of Nova Xavantina - MT, ii) identify the origin of these species, if native or exotic; and, iii) check for similarity in floristic composition among these squares. This research study area was the 12 squares of the municipality. The floristic identification occurred through visits to squares, identifying in situ and consult to Herbarium NX. There were found 851 individuals belonging to 86 species and 28 families. The families with higher species richness were Fabaceae (20 species), Arecaceae (12) and Bignoniaceae (10). Most families had of one to three species. Of the total species found $55 \%$ are native. The floristic similarity among the squares of the city is low because only three groups showed high similarity, thus revealing that a diversity of species is being used in afforestation of squares of the city.

Keywords: Green areas; Quality of life; Species richness.

Recebido em 22.09.2015 e aceito em 20.11.2015

1 Bióloga, Universidade do Estado de Mato Grosso - UNEMAT, Campus de Nova Xavantina/MT. Email: jesianelima@hotmail.com

2 Biólogo, Mestre em Ecologia e Conservação, Universidade do Estado de Mato Grosso, UNEMAT, Campus de Nova Xavantina/- MT. Email: carlos.kreutz@hotmail.com

3 Bióloga, Mestre em Ecologia e Conservação, Universidade do Estado de Mato Grosso, UNEMAT, Campus de Nova Xavantina - MT. Email: orialespereira@yahoo.com.br 


\section{INTRODUÇÃO}

De maneira geral, as praças se localizam em locais públicos próximos da população, tem como finalidade proporcionar condições agradáveis aos frequentadores e são vistas como ambiente de lazer para atender as necessidades da vida urbana (CARVALHO; NUCCI; VALASKI, 2010), espaço para contemplação da natureza e vida mais saudável para todas as idades e classes sociais (SANTOS; SANTOS; GOMES, 2014).

Em cidades onde ocorre o planejamento da arborização desses locais, o cuidado é em utilizar diversidade de espécies vegetais do bioma ao qual a cidade está inserida, para compor o ambiente urbano com diversidade de espécies entre as praças, mantendo as características vegetacionais regional (MELO; ROMANINI, 2008), sendo importante o manejo adequado e o conhecimento do componente arbóreo para arborização, evitando assim, prejuízo ao meio ambiente (DANTAS; SOUZA, 2004). No entanto, na maioria das cidades é possível observar um padrão de arborização irregular, inadequada e descontínua (SILVA et al., 2008).

Conhecer as espécies vegetais presentes nessas praças é uma forma de proporcionar conhecimento e, posteriormente contribuir com trabalhos que abordam as necessidades da vida urbana, como planejamento da arborização de novas áreas, considerando as espécies da região no momento do plantio e conservando características naturais do bioma (DANTAS; SOUZA, 2004).

Tendo em vista que até o momento não se tem trabalhos realizados com a identificação das espécies vegetais incorporadas na arborização das praças do município de Nova Xavantina - MT, este estudo possui grande relevância para a comunidade local e científica, pois é importante para o manejo adequado e o conhecimento do componente arbóreo, evitando assim, prejuízo ao meio ambiente (DANTAS; SOUZA, 2004). Este trabalho teve como objetivos: i) realizar o levantamento das espécies arbóreas das praças públicas no município de Nova Xavantina - MT, identificando as espécies e suas respectivas famílias; ii) identificar a origem dessas espécies, classificando-as se nativas ou exóticas; e, iii) verificar se há similaridade na composição florística das praças públicas do município.

\section{MATERIAL E MÉTODOS}

\section{Área de Estudo}

O estudo foi realizado na cidade de Nova Xavantina, localizada na região leste de Mato

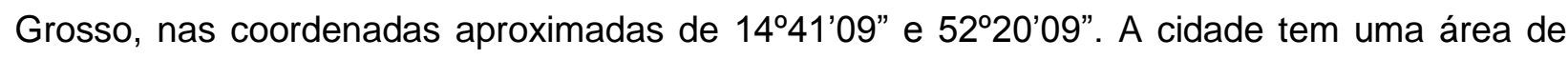
$5.573,682 \mathrm{~km}^{2}$, com a população estimada em 20.143 habitantes. Faz limites com Água Boa, 
Nova Nazaré, Cocalinho, Araguaiana, Barra do Garças, Novo São Joaquim e Campinápolis (IBGE, 2013).

O município está inserido em uma região de transição entre o bioma Cerrado e Floresta Amazônica, apresentando vegetação predominante de cerrado sensu stricto e presença de extensas áreas de matas e manchas de cerradão, com relevo caracterizado como plano a ondulado, em altitudes entre 250 a 300 metros e com ocorrências de solos do tipo litólicos, cambissolo transicional com deposição de blocos de quartzito e latossolo vermelho-amarelo (MARIMON-JUNIOR; HARIDASAN, 2005; RADAMBRASIL, 1981).

Possui clima do tipo Aw, de acordo com a classificação de Köppen, tropical quente e sub-úmido, apresentando duas estações bem definidas: uma seca e fria e outra quente e chuvosa, sendo o período seco de maio a setembro e o chuvoso de outubro a abril, com precipitação e temperatura média anual de $1.520 \mathrm{~mm}$ e $24,8^{\circ} \mathrm{C}$, respectivamente, sendo as médias mensais mínimas de 100 e máximas de 37,4ํㅡ (MARIMON et al., 2010).

A área de estudo compreende as 12 praças do município de Nova Xavantina - MT, sendo: PC1 - Praça Aldenor Rodrigues Magalhães; PC2 - Praça Suzinete Ferreira da Silva; PC3 - Praça Luiza Pereira dos Santos; PC4 - Praça Padre José Mota; PC5 - Praça Dom Bosco; PC6 - Praça dos Pioneiros; PC7 - Praça Hermes Jefferson de Souza; PC8 - Praça Raimundo Ricardo Alves; PC9 - Praça José Mauricio Barbosa; PC10 - Praça Dona Rosa Ferreira Lima; PC11 - Praça dos Três Poderes; PC12 - Praça José Alencar Soares. Essas são todas as praças do município. As praças Luiza Pereira dos Santos e Praça Suzinete Ferreira da Silva estavam sendo construídas e arborizadas pela prefeitura no momento do desenvolvimento deste trabalho, assim mesmo foi realizado o levantamento florístico das espécies que ali já estavam.

\section{Levantamento Florístico}

Para o levantamento florístico foram realizadas visitas a cada praça, entre os meses de julho a outubro de 2013, para a identificação das espécies de árvores, arbustos e palmeiras que compõem a arborização.

O método empregado na identificação das espécies foi o de análise visual, anotando seu nome vulgar ou científico (proporcionado pela população, por profissional da área ou bibliografia especializada). Quando não foi possível a identificação em campo, realizou-se o registro fotográfico, fez-se anotações de cunho morfológico da planta, como as características de seus órgãos vegetativos (porte da árvore, estrutura e coloração do caule, tipo de folha, filotaxia foliar, nervuras, etc.) e reprodutivos (ocorrência de flores e frutos e suas classificações) para facilitar a posterior identificação. 
Quando necessário, foi feita a coleta do material vegetativo e reprodutivo para análise e comparação com espécimes já herborizados, pertencentes à coleção Zoobotânica James Alexander Ratter, do Herbário NX no Campus de Nova Xavantina (UNEMAT).

Após a identificação, fez-se a contagem do número de indivíduos de cada espécie presente na praça, estimando assim a sua abundância. Para a correta nomenclatura das espécies, classificação das famílias e sua origem (nativa ou exótica), foi realizada consulta ao APG III (2009).

\section{Análise de Dados}

O cálculo da frequência das espécies de maior ocorrência foi feito através da razão entre o número de indivíduos da espécie e o número de indivíduos total.

Para verificar a similaridade florística entre as praças, foi realizado a Análise de Agrupamento (Cluster), sendo utilizada para isso a presença/ausência das espécies em cada praça. Foi utilizado o índice de Similaridade de Jaccard e o método de ligação UPGMA (Unweighted Pair Group Method Average). De acordo com Muller-Dumbois e Ellenberg, (1974), agrupamentos com valores de similaridade maiores que 0,25 são considerados similares. Esta análise foi baseada na fórmula $(C j)=C / A+B-C$, onde $A$ é a riqueza de espécies da área $A$, $B$ é a riqueza de espécies da área $\mathrm{B}$ e $\mathrm{C}$ é o número de espécies comuns às duas áreas (MULLERDUMBOIS; ELLENBERG, 1974).

\section{RESULTADOS E DISCUSSÃO}

\section{Análise Florística}

Foi registrado nas 12 praças públicas analisadas um total de 851 indivíduos, de 86 espécies, distribuídos em 28 famílias botânicas, apenas três indivíduos não foram identificados (Tabela 1). Para as espécies Duranta repens L. e Ixora chinensis Lam., não foi considerado o número de indivíduos, pois as mesmas foram encontradas em arredores de canteiros públicos servindo como cercas vivas. 
Tabela 1. Árvores, arbustos e palmeiras encontradas em 12 praças públicas de Nova Xavantina/MT, em 2013

Table 1. Trees, shrubs and palm trees found in 12 public squares of Nova Xavantina/MT, in 2013

\begin{tabular}{|c|c|c|c|c|c|c|c|c|c|c|c|c|c|c|c|c|}
\hline \multirow{3}{*}{$\begin{array}{l}\text { Família/Espécie } \\
\text { ANACARDIACEAE }\end{array}$} & \multirow{3}{*}{ Nome vulgar } & \multirow{3}{*}{ N/E } & \multicolumn{14}{|c|}{ Abundância de Indivíduos } \\
\hline & & & \multirow{3}{*}{\multicolumn{3}{|c|}{$\begin{array}{lll}\text { P1 } & \text { P2 } & \text { P3 } \\
0 & 0 & 1\end{array}$}} & \multirow[t]{2}{*}{ P4 } & \multirow{2}{*}{\multicolumn{2}{|c|}{ P5 P6 }} & \multirow[b]{3}{*}{13} & \multirow[t]{2}{*}{ P8 } & \multirow[b]{3}{*}{0} & \multirow[b]{3}{*}{0} & & & & $F(\%)$ \\
\hline & & & & & & & & & & & & & & & & \\
\hline Anacardium occidentale L. & Cajueiro & $\mathrm{N}$ & & & & 0 & 7 & 4 & & 5 & & & 2 & 0 & 32 & 3,76 \\
\hline Astronium sp. & 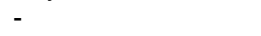 & $\mathrm{N}$ & 0 & 0 & 0 & 0 & 1 & 0 & 0 & 0 & 0 & 0 & 4 & 0 & 5 & 0,59 \\
\hline Mangifera indica $\mathrm{L}$. & Mangueira & $\mathrm{E}$ & 1 & 0 & 1 & 2 & 7 & 2 & 8 & 1 & 0 & 5 & 5 & 3 & 35 & 4,11 \\
\hline Myracrodruon urundeuva Allemão & Aroeira & $\mathrm{N}$ & 0 & 0 & 0 & 0 & 1 & 0 & 2 & 0 & 0 & 0 & 0 & 0 & 3 & 0,35 \\
\hline Spondias purpurea L. & Seriguela & $\mathrm{E}$ & 0 & 0 & 0 & 0 & 1 & 0 & 0 & 0 & 0 & 0 & 0 & 0 & 1 & 0,12 \\
\hline APOCYNACEAE & & & & & & & & & & & & & & & & \\
\hline Allamanda cathartica $\mathrm{L}$. & Alamanda-amarela & $\mathrm{N}$ & 0 & 0 & 0 & 0 & 2 & 0 & 0 & 0 & 0 & 0 & 0 & 0 & 2 & 0,24 \\
\hline Hancornia speciosa Gomes & Mangaba & $\mathrm{N}$ & 0 & 0 & 0 & 0 & 0 & 0 & 2 & 0 & 0 & 0 & 0 & 0 & 2 & 0,24 \\
\hline Nerium oleander $\mathrm{L}$. & Espirradeira & $\mathrm{E}$ & 0 & 0 & 0 & 1 & 0 & 0 & 0 & 0 & 0 & 0 & 0 & 0 & 1 & 0,12 \\
\hline ARECACEAE & & & & & & & & & & & & & & & & \\
\hline Acrocomia aculeata ( & Maca & $\mathrm{N}$ & 0 & 0 & 0 & 0 & 3 & 0 & 6 & 0 & 0 & 0 & 2 & 0 & & 1,29 \\
\hline Attalea geraensis Bar & Indaiá-do-cerrado & $\mathrm{N}$ & 0 & 0 & 0 & 0 & 0 & 0 & 0 & 0 & 0 & 0 & 3 & 0 & 3 & 0,35 \\
\hline Caryota urens L. & $\begin{array}{l}\text { Palmeira-rabo-de- } \\
\text { peixe }\end{array}$ & $E$ & 0 & 0 & 0 & 2 & 0 & 0 & 0 & 0 & 0 & 0 & 2 & 0 & 4 & 0,47 \\
\hline Dypsis lastelliana (Baill.) Beentje. J.Drans. & Palmeira-de- & $\mathrm{E}$ & 0 & 0 & 0 & 0 & 0 & 0 & 0 & 0 & 0 & 0 & 1 & 3 & 4 & 0,47 \\
\hline Dypsis lutescens H. Wendl. & Areca-bambu & $E$ & 0 & 0 & 0 & 6 & 0 & 0 & 0 & 0 & 0 & 0 & 8 & 0 & 14 & 1,65 \\
\hline Livistona rotundifolia & Palme & $\mathrm{E}$ & 0 & 0 & 0 & 1 & 0 & 0 & 0 & 0 & 0 & 0 & 12 & 0 & 3 & 1,53 \\
\hline Phoenix roebelenii O'Brien & Tamareira-anã & E & 0 & 0 & 0 & 4 & 0 & 0 & 0 & 0 & 0 & 0 & 12 & 0 & 16 & 1,88 \\
\hline $\begin{array}{l}\text { Roystonea oleracea (N.J.Jacquim) O. F. } \\
\text { Cook }\end{array}$ & Palmeira-Imperial & $\mathrm{E}$ & 0 & 0 & 0 & 2 & 0 & 2 & 0 & 0 & 0 & 0 & 2 & 2 & 8 & 0,94 \\
\hline $\begin{array}{l}\text { Scheelea phalerata (Mart. ex Spreng.) } \\
\text { Burret }\end{array}$ & Bacuri & $\mathrm{N}$ & 0 & 0 & 0 & 0 & 1 & 0 & 0 & 10 & 0 & 2 & 1 & 0 & 14 & 1,65 \\
\hline Syagrus oleracea (Mart.) Becc. & Gueroba & $\mathrm{N}$ & 0 & 0 & 2 & 0 & 2 & 5 & 5 & 0 & & 32 & 29 & 01 & & 15,4 \\
\hline Washingtonia filifera (Linden) H. Wendl. & $\begin{array}{l}\text { Palmeira-de-saia- } \\
\text { da-Califórnia }\end{array}$ & $E$ & 0 & 0 & 0 & 2 & 0 & 0 & 0 & 0 & 0 & 0 & 0 & 0 & 2 & 0,24 \\
\hline BIGNONIACEAE & & & & & & & & & & & & & & & & \\
\hline Handroanthus heptaphyllus (Vell.) Mattos & Ipê-roxo & $\mathrm{N}$ & 0 & 0 & 0 & 0 & 4 & 0 & 0 & 0 & 0 & 0 & 0 & 6 & 10 & 1,18 \\
\hline $\begin{array}{l}\text { Handroanthus serratifolius (Vahl.) S. O. } \\
\text { Grose }\end{array}$ & Ipê-amarelo & $\mathrm{N}$ & 0 & 0 & 0 & 0 & 16 & 10 & 11 & 5 & 0 & 0 & 2 & 6 & 50 & 5,88 \\
\hline Jacaranda brasiliana (Lam.) Pers & da-boca- & $\mathrm{N}$ & 0 & 0 & 0 & 0 & 1 & 4 & 9 & 1 & 0 & 0 & 0 & 0 & 15 & 1,76 \\
\hline Spathodea campanu & Xixi- de- macaco & $\mathrm{E}$ & 0 & 0 & 0 & 0 & 0 & 0 & 0 & 0 & 0 & 0 & 0 & 1 & 1 & 0,12 \\
\hline $\begin{array}{l}\text { Tabebuia aurea (Manso) Benth. \& Hook. } \\
\text { F. ex S. Moore }\end{array}$ & Caraíba & $\mathrm{N}$ & 0 & 0 & 0 & 0 & 3 & 0 & 0 & 0 & 0 & 0 & 0 & 0 & 3 & 0,35 \\
\hline Tabebuia ochracea (Cham.) Standl. & Ip & $\Lambda$ & 0 & 0 & 0 & 0 & 0 & 0 & 0 & 2 & 0 & 0 & 0 & 0 & 2 & 0,24 \\
\hline Tabebuia roseo alba ( $\mathrm{F}$ & lpê-b & $\mathrm{N}$ & 0 & 0 & 0 & 0 & 5 & 0 & 0 & 0 & 0 & 0 & 0 & 1 & 6 & 0,71 \\
\hline Tabe & & $N$ & 0 & 28 & 5 & 0 & 0 & 0 & 0 & 0 & 0 & 0 & 0 & 0 & 33 & 3,88 \\
\hline stans (L.) Jus & Ip & $\mathrm{D}_{2}$ & 0 & 0 & 0 & 0 & 2 & 0 & 0 & 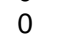 & 0 & 0 & 0 & 0 & 2 & 0,24 \\
\hline BOMBACACEAE & & & & & & & & & & & & & & & & \\
\hline Aubl. & Mor & $\mathrm{N}$ & 0 & 0 & 0 & 0 & 4 & 1 & 0 & 1 & 1 & 1 & 2 & 0 & 10 & 1,18 \\
\hline$\overline{\text { CAR }}$ & & & & & & & & & & & & & & & & \\
\hline Cary & Pequi & $\mathrm{N}$ & 0 & 0 & 0 & 0 & 0 & 1 & 3 & 0 & 0 & 0 & 0 & 0 & 4 & 0,47 \\
\hline$\overline{\mathrm{CHR}}$ & & & & & & & & & & & & & & & & \\
\hline omentosa (Be & Oiti & $\mathrm{N}$ & 0 & 0 & 0 & 1 & 0 & 0 & 2 & 0 & 0 & 5 & 4 & 1 & 13 & 1,53 \\
\hline$\overline{\text { CLUSIACEAE }}$ & & & & & & & & & & & & & & & & \\
\hline Calo & Gua & $\mathrm{N}$ & 0 & 0 & 0 & 0 & 0 & 6 & 4 & 0 & 0 & 0 & 0 & 0 & 10 & 1,18 \\
\hline $\mathrm{COI}$ & & & & & & & & & & & & & & & & \\
\hline Buc & & 11 & 0 & 0 & 0 & 2 & 0 & 0 & 0 & 0 & 0 & 0 & 0 & & & 0,24 \\
\hline Termi & & 5 & 0 & 0 & 3 & 0 & 0 & 0 & 1 & 0 & 0 & 0 & 2 & 0 & & 0,71 \\
\hline SACEAE & & & & & & & & & & & & & & & & \\
\hline & Cipre & $\mathrm{E}$ & 0 & 0 & 0 & 3 & 0 & 0 & 0 & 0 & 0 & 0 & 1 & 0 & 4 & 0,47 \\
\hline$\overline{\text { CYCP }}$ & & & & & & & & & & & & & & & & \\
\hline voluta Thunb. & Cica & $\mathrm{E}$ & 0 & 0 & 0 & 3 & 0 & 0 & 0 & 0 & 0 & 0 & 5 & 0 & 8 & 0,94 \\
\hline DILLENIACEAE & & & & & & & & & & & & & & & & \\
\hline americana L. & Lixeira & $\mathrm{N}$ & 0 & 0 & 0 & 0 & 0 & 0 & 1 & 0 & 0 & 0 & 0 & 0 & 1 & 0,12 \\
\hline FARA & & & & & & & & & & & & & & & & \\
\hline thera sp. & & $\mathrm{N}$ & 0 & 0 & 0 & 0 & 0 & 0 & 1 & 6 & 0 & 0 & 0 & 0 & & 0,82 \\
\hline & & $\mathrm{N}$ & 0 & 0 & 0 & 0 & 0 & 0 & 0 & 0 & 0 & 0 & 1 & 0 & & 0,12 \\
\hline Bauhinia va & Unh & $\mathrm{F}$ & 0 & 1 & 0 & 0 & 0 & 0 & 0 & 0 & 0 & 0 & 0 & 0 & & 0,12 \\
\hline a lelostach & & $\mathrm{N}$ & 1 & 0 & 0 & 0 & 0 & 0 & 0 & 0 & 3 & 0 & 0 & 0 & 4 & 0,47 \\
\hline Caesalpinia pluviosa Var. & Sibipurina & $\mathrm{N}$ & 0 & 0 & 0 & 0 & 2 & 0 & 0 & 9 & 2 & 2 & 8 & 0 & 23 & 2,7 \\
\hline Caesalpinia pulcherrima L. & $\begin{array}{l}\text { Flamboyant-de- } \\
\text { jardim }\end{array}$ & $E$ & 0 & 0 & 0 & 0 & 1 & 0 & 0 & 0 & 0 & 0 & 0 & 0 & 1 & 0,12 \\
\hline Cassia ferruginea (Schrad.) & $\begin{array}{l}\text { Canafístula-de- } \\
\text { besouro }\end{array}$ & E & 0 & 0 & 0 & 0 & 0 & 0 & 0 & 8 & 0 & 14 & 0 & 0 & & 9 \\
\hline
\end{tabular}




\begin{tabular}{|c|c|c|c|c|c|c|c|c|c|c|c|c|c|c|c|c|}
\hline Clitoria fairchildiana R.A. Howard & Sombra-de-vaca & $\mathrm{N}$ & 1 & 0 & 0 & 0 & 2 & 0 & 0 & 1 & 0 & 1 & 12 & 0 & & 2 \\
\hline Delonix regia (Bojer ex Hook.) Raf. & Flamboyant & $\mathrm{E}$ & 0 & 0 & 0 & 0 & 5 & 0 & 1 & 0 & 0 & 1 & 0 & 2 & 9 & 1,06 \\
\hline Dipteryx alata Vogel. & Baru & $\mathrm{N}$ & 0 & 2 & 0 & 0 & 4 & 1 & 8 & 0 & 1 & 0 & 0 & 0 & & 1,88 \\
\hline $\begin{array}{l}\text { Enterolobium contortisliquum (Vell.) } \\
\text { Morong }\end{array}$ & Orelha-de-macaco & $\mathrm{N}$ & 0 & 0 & 0 & 0 & 0 & 0 & 0 & 3 & 0 & 0 & 0 & 0 & 3 & 0,35 \\
\hline Hymenaea stignocarpa Mart. & Jabotá & $\mathrm{N}$ & 0 & 0 & 1 & 0 & 5 & 5 & 9 & 7 & 0 & 0 & 0 & 0 & 27 & 3,17 \\
\hline Inga sp. & Ingá & $\mathrm{N}$ & 0 & 9 & 0 & 0 & 2 & 0 & 0 & 6 & 0 & 0 & 1 & 27 & 45 & 5,29 \\
\hline Peltophorum dubium (Spreng.) Taub. & Canafístula & $\mathrm{N}$ & 0 & 0 & 0 & 2 & 0 & 0 & 0 & 3 & 0 & 0 & 0 & 0 & 5 & 0,59 \\
\hline Tamarindus indica $\mathrm{L}$ & Tamarindo & $\mathrm{E}$ & 0 & 0 & 0 & 0 & 1 & 0 & 1 & 0 & 0 & 0 & 0 & 0 & 2 & 0,24 \\
\hline Fabaceae (1) & - & - & 2 & 0 & 0 & 5 & 0 & 0 & 0 & 0 & 0 & 0 & 0 & 0 & 7 & 0,82 \\
\hline Fabaceae (2) & - & - & 0 & 0 & 0 & 0 & 5 & 2 & 0 & 0 & 0 & 7 & 2 & 0 & 16 & 1,88 \\
\hline Fabaceae (3) & - & - & 0 & 0 & 0 & 0 & 0 & 0 & 0 & 3 & 0 & 0 & 0 & 0 & 3 & 0,35 \\
\hline Fabaceae (4) & - & - & 0 & 0 & 0 & 0 & 0 & 0 & 2 & 0 & 0 & 0 & 0 & 0 & 2 & 0,24 \\
\hline Fabaceae (5) & . & - & 0 & 0 & 0 & 0 & 0 & 0 & 0 & 1 & 0 & 0 & 0 & 0 & 1 & 0,12 \\
\hline LAMIACEAE & & & & & & & & & & & & & & & & \\
\hline Congea tomentosa Var. & Trepadeira & $\mathrm{E}$ & 0 & 0 & 0 & 0 & 0 & 0 & 0 & 0 & 0 & 0 & 0 & 1 & 1 & 0,12 \\
\hline LILIACEAE & & & & & & & & & & & & & & & & \\
\hline Dracaena fragrans (L.) Ker Gawl. & Coqueiro-de-vênus & $\mathrm{E}$ & 0 & 0 & 0 & 0 & 0 & 0 & 0 & 0 & 0 & 0 & 3 & 0 & 3 & 0,35 \\
\hline MALPIGHIACEAE & & & & & & & & & & & & & & & & \\
\hline Lophantera lactescens Ducke. & $\begin{array}{l}\text { Chuva-de-ouro-da- } \\
\text { Amazônia }\end{array}$ & $\mathrm{N}$ & 0 & 0 & 0 & 0 & 0 & 0 & 6 & 0 & 0 & 4 & 0 & 1 & 11 & 1,29 \\
\hline Malpighia glabra L. & Acerola & $\mathrm{N}$ & 0 & 0 & 0 & 3 & 0 & 0 & 0 & 0 & 0 & 0 & 0 & 0 & 3 & 0,35 \\
\hline MALVACEAE & & & & & & & & & & & & & & & & \\
\hline Hibiscus rosa-sinensis Linn. & Hibis & $\mathrm{E}$ & 0 & 0 & 0 & 0 & 0 & 0 & 0 & 0 & 0 & 0 & 2 & 11 & 13 & 1,53 \\
\hline Luehea sp. & Açoita-cavalo & $\mathrm{N}$ & 0 & 0 & 0 & 0 & 0 & 0 & 2 & 0 & 0 & 0 & 0 & 0 & 2 & 0,24 \\
\hline Sterculia chicha A. St.-Hil. \& Naudin & Chich & $\mathrm{N}$ & 0 & 0 & 0 & 0 & 0 & 0 & 1 & 0 & 0 & 0 & 0 & 0 & 1 & 0,12 \\
\hline MELIACEAE & & & & & & & & & & & & & & & & \\
\hline Cedrela odorata L. & Cedro & $\mathrm{N}$ & 0 & 0 & 0 & 0 & 0 & 2 & 2 & 0 & 0 & 0 & 0 & 0 & 4 & 0,47 \\
\hline MORACEAE & & & & & & & & & & & & & & & & \\
\hline Arthocarpus heterophyllus Lam. & Jaq & $\mathrm{E}$ & 0 & 0 & 0 & 0 & 0 & 0 & 1 & 0 & 0 & 0 & 0 & 1 & 2 & 0,24 \\
\hline Idichaudii Trecul. & Mama-cadela & $\mathrm{N}$ & 0 & 0 & 0 & 0 & 0 & 2 & 0 & 0 & 0 & 0 & 0 & 0 & 2 & 0,24 \\
\hline Ficus benjamina $\mathrm{L}$. & Ficus & $\mathrm{E}$ & 0 & 0 & 0 & 0 & 0 & 20 & 0 & 0 & 0 & 0 & 0 & 0 & 20 & 2,35 \\
\hline Ficus sp. & Gameleira & $\mathrm{E}$ & 0 & 0 & 0 & 0 & 1 & 0 & 0 & 1 & 0 & 0 & 3 & 0 & 5 & 0,59 \\
\hline MYRTACEAE & & & & & & & & & & & & & & & & \\
\hline Eucalyptus globulus Labill. & Eucalipto & $\mathrm{E}$ & 0 & 0 & 0 & 0 & 2 & 0 & 0 & 0 & & & & 0 & & 0,24 \\
\hline Eucalyptus sp. & & $\mathrm{E}$ & 0 & 0 & 0 & 0 & 0 & 0 & 0 & 0 & 0 & 5 & 0 & 0 & 5 & 0,59 \\
\hline Eugenia malaccensis L. & Jamb & $\mathrm{E}$ & 0 & 0 & 0 & 0 & 1 & 0 & 0 & 0 & 0 & 0 & 0 & 0 & 1 & 0,12 \\
\hline Eugenia uniflora L. & Pitanga & $\mathrm{N}$ & 0 & 0 & 0 & 0 & 1 & 0 & 7 & 0 & 0 & 0 & 0 & 0 & 8 & 0,94 \\
\hline Myrciaria cauliflora (Mart.) Berg. & Jabuticabeira & $\mathrm{N}$ & 0 & 0 & 0 & 0 & 5 & 0 & 0 & 0 & 0 & 0 & 0 & 0 & 5 & 0,59 \\
\hline Psidium guajava $L$. & Goiabeira & $\mathrm{N}$ & 0 & 0 & 0 & 1 & 0 & 1 & 1 & 0 & 0 & 0 & 0 & 0 & 3 & 0,35 \\
\hline Syzygium cumini (L.) & Jamelão & $\mathrm{E}$ & 0 & 0 & 0 & 0 & 0 & 0 & 0 & 2 & 0 & 3 & 0 & 0 & 5 & 0,59 \\
\hline
\end{tabular}

\section{NYCTAGIACEAE}

Bougainvillea glabra Choisy var.

graciliflora

Primavera

$\begin{array}{lllllllllllllll}\mathrm{N} & 0 & 0 & 0 & 0 & 0 & 0 & 0 & 0 & 0 & 0 & 0 & 2 & 2 & 0,24\end{array}$

OLEACEAE

Jasminum sp.

PINACEAE

Pinus sp.

Genipa americana L.

Ixora chinensis Lam.

RUTACEAE

Citrus limonium L.

Citrus sinensis (L.) Osbeck.

Zanthoxylum rhoifolium Lam.

Zanthoxylum sp.

SAPOTACEAE

Pouteria macrophylla (Lam.) Eyma

STERCULIACEAE

Guazuma ulmifolia Lam.

VERBENACEAE

Duranta repens L.

NÃO IDENTIFICADA

$\mathrm{NI}-1$ (Liana 01)

$\mathrm{NI}-2$

$\mathrm{NI}-3$ (Liana 02)

\begin{tabular}{llllllllllllllll} 
Jasmim-branco & $\mathrm{E}$ & 0 & 0 & 0 & 0 & 0 & 0 & 0 & 0 & 0 & 0 & 0 & 7 & 7 & 0,82 \\
\hline
\end{tabular}

$\begin{array}{llllllllllllllll}\text { Pinos } & E & 0 & 0 & 0 & 0 & 0 & 0 & 0 & 0 & 0 & 0 & 2 & 0 & 2 & 0,24\end{array}$

$\begin{array}{lllllllllllllllll}\text { Jenipapo } & \mathrm{N} & 0 & 0 & 0 & 0 & 3 & 0 & 2 & 0 & 0 & 0 & 0 & 0 & 5 & 0,59\end{array}$
Ixora

$\mathrm{E} \quad 0 \quad 0 \quad 0+000000000$

Limoeiro

$\begin{array}{lllllllllllllll}\mathrm{E} & 0 & 0 & 0 & 0 & 0 & 0 & 1 & 0 & 0 & 0 & 0 & 0 & 1 & 0,12\end{array}$

Espinhosa

$\mathrm{E} \quad 00 \begin{array}{llllllllllllll} & 0 & 0 & 0 & 1 & 0 & 0 & 0 & 0 & 0 & 0 & 0 & 1 & 0,12\end{array}$

Nota: N: Nativa; E: Exótica; +: quantidade indeterminada. P1: Praça Aldenor Rodrigues Magalhães; P2: Praça Suzinete Ferreira da Silva; P3: Praça Luiza Pereira dos Santos; P4: Praça Padre José Mota; P5: Praça Dom Bosco; P6: Praça dos Pioneiros; P7: Praça Hermes Jefferson de Souza; P8: Praça Raimundo Ricardo Alves; P9: Praça José Mauricio Barbosa; P10: Praça Dona Rosa Ferreira Lima; P11: Praça dos Três Poderes; P12: Praça José Alencar Soares; TO: total; F: Frequência relativa. 
O número total de espécies $(S=86)$ é elevado quando comparado com valores obtidos em pesquisas semelhantes, como os trabalhos de Souza et al. (2011) que identificaram 64 espécies em 22 praças em Aracaju/SE; Pestana, Alves e Sartori (2011) registraram para duas praças, quatro avenidas e 18 ruas, um total de 61 espécies na cidade de Cacoal/RO; e Neto et al. (2007), também em Aracajú/SE, verificaram apenas 23 espécies arbóreas em seis praças e canteiros centrais de 12 avenidas. Com base nestas comparações, percebe-se um alto valor de riqueza de espécies distribuídas nas praças de Nova Xavantina. Em relação ao número de indivíduos, este foi relativamente baixo $(n=851)$ quando comparado aos mesmos trabalhos, Souza et al. (2011) e Neto et al. (2007) registraram 1.290 e 1.076 indivíduos, respectivamente. $\mathrm{O}$ que pode ter contribuído para o menor número de indivíduos no presente trabalho foi a quantidade de áreas analisadas menor quando comparada aos estudos citados. Este número de praças existentes em Nova Xavantina está diretamente relacionado ao seu tamanho, visto que é uma cidade menor que a dos estudos comparados.

A quantidade de famílias observadas (28) é considerada baixa quando comparada aos trabalhos de Kramer e Krupek (2012), que relataram 43 famílias em sete praças na cidade de Guarapuava/PR. Esse baixo número de famílias possivelmente está relacionado com planos de arborização das praças do município, que possivelmente priorizam a riqueza de espécies e não a diversidade de famílias, pois pode haver uma maior riqueza de espécie distribuída em poucas famílias.

As famílias que apresentaram maiores riquezas de espécies foram Fabaceae (20 espécies), Arecaceae (12), Bignoniaceae (10), Myrtaceae (sete), Anacardiaceae (cinco), Moraceae e Rutaceae (quatro cada) (Figura 1). Porém, a maioria das famílias (22 famílias, $75 \%$ ) apresentou de uma a três espécies apenas.

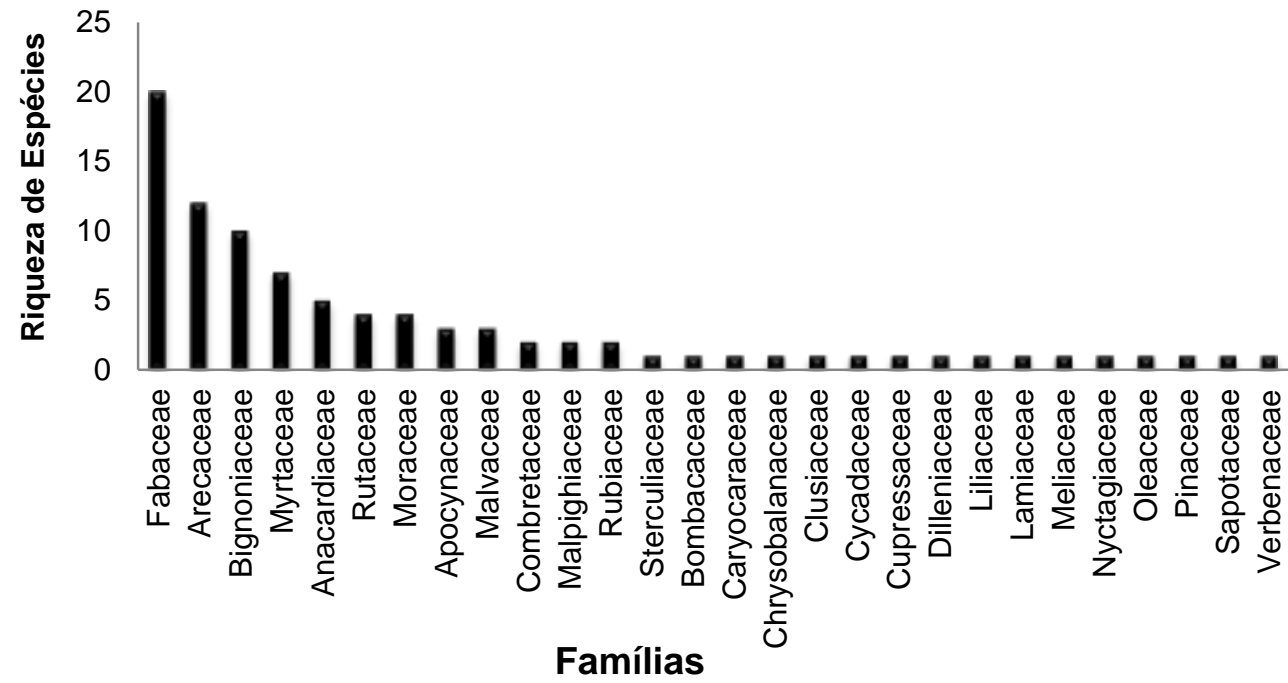

Figura 1. Riqueza de espécies das famílias encontradas nas praças públicas avaliadas em Nova Xavantina /MT

Figure 1. Species richness of families found in public squares evaluated in Nova Xavantina/MT 
A família Fabaceae apresenta cerca de 18.000 espécies e mais de 600 gêneros, sendo considerada uma das maiores famílias de angiospermas e está distribuída em quase todas as regiões do mundo, com grande número de táxons endêmicos (JOLY, 2002; MOURÃO; KARAM; SILVA, 2011). Vale et al. (2011), também registraram maior ocorrência de Fabaceae no Parque da cidade de Sobral/CE. A família é procurada para fins ornamentais por apresentar exuberância no tempo de floração, com flores e frutos variados, e ainda são inúmeras as espécies utilizadas para consumo humano e animal (MOURÃO; KARAM; SILVA, 2011).

Um fator importante que contribui com a intensa presença de espécies das famílias Myrtaceae e Anacardiaceae na arborização de áreas verdes municipais, de acordo com Kramer e Krupek (2012), está diretamente relacionado ao fato destas serem famílias que possuem a maioria de suas espécies como sendo espécies produtoras de frutos comestíveis, proporcionando além do fator ornamentação, alimento para fauna e para a comunidade em si. Das 86 espécies amostradas neste estudo, 27 tem frutos consumidos pelo homem.

Arecaceae (27\% do total de indivíduos), Bignoniaceae (14\%) e Moraceae $(3,4 \%)$ (Tabela 1) tiveram um número de espécies e de indivíduos bem representativo no presente estudo. Arecaceae é representada pelas palmeiras, com grande importância econômica na produção de matéria-prima, na comercialização de produtos alimentícios, e possui valor estético agregado as suas espécies, valor este que a muitos séculos é utilizado no paisagismo de praças e jardins públicos (JOLY, 2002). As espécies mais representativas da família Arecaceae foram Syagrus oleracea (15\% do total), Phoenix roebelenii $(1,8 \%)$ e Dypsis lutescens $(1,6 \%)$ (Tabela 1$)$. Syagrus oleracea é uma espécie nativa do Cerrado, e sua maior representatividade entre as palmeiras pode estar relacionada à fácil produção de mudas e rápido desenvolvimento em ambientes de Cerrado (AMARAL; GUILHERME, 2014). Ainda de acordo com os autores, a espécie apresenta folhas que não favorecem à produção de sombra para a população que faz uso das praças.

A família Bignoniaceae foi representada pelos ipês, sendo Handroanthus serratifolius (5,8\%), Tabebuia sp. (3,8\% do total) e Jacaranda brasiliana com (1,8\%). Essas árvores esbanjam exuberância em épocas de floração, sendo frequentemente empregadas em arborização, pois é um grande sucesso na utilização em paisagismo (JOLY, 2002).

Outra família que teve destaque foi Rutaceae com 22 indivíduos (2,5\% do total), com predomínio de Zantroxylum rhoinfolium que apresentou 18 indivíduos (2,1\%). Moraceae teve predomínio da espécie Ficus benjamina (2,4\%). No Brasil os gêneros que predominam nesta família são Brosimum, Cecropia, Dorstenia e Ficus, porém o maior gênero da família é o Ficus, com cerca de 600 espécies (JOLY, 2002). A espécie F. benjamina é exótica de origem Asiática. Possui uso diverso, mas se destaca na ornamentação de canteiros, calçadas e praças (SANTOS; RAMALHO, 1997). 
Foi possível perceber que o seu uso na ornamentação das praças de Nova Xavantina está em um nível de presença adequado, pois sua frequência de indivíduos não ultrapassou 15\% (Tabela 1), sendo um valor adequado de acordo com Grey e Deneke (1978), pois esses autores recomendam que cada espécie não deve exceder de $10-15 \%$ do total de indivíduos para um bom planejamento, garantindo uma diversidade equilibrada.

No levantamento pode ser verificado que a maior parte das espécies (50 espécies, 55\% do total) é de origem nativa do território brasileiro. Em Nova Xavantina, há possibilidade de aumentar o plantio de espécies nativas em projeto de arborização do município, necessitando maior atenção para a utilização de plantas nativas na arborização de futuras praças, tento em vista valorizar características do local, juntamente com sua preservação e o equilíbrio, fornecido pelo bioma nativo.

A maioria das plantas exóticas encontradas nas praças de Nova Xavantina é originária da Ásia, Índia e África, como: Cycas revoluta, Ficus benjamina, Mangifera indica, Phoenix roebelenii, Roystonea oleracea e Terminalia catappa, o que possivelmente ocorre em virtude dessas espécies se adaptarem bem ao clima tropical da região, portanto se mantendo no ambiente e, também, as escolhas dessas espécies para inserção nos processos de arborização do município ocorre devido ao pouco conhecimento ecológico proporcionado por um plano de arborização adequado, evidenciando a opção por espécies tradicionalmente utilizadas na arborização de outros locais.

Embora as espécies exóticas sejam procuradas por apresentar fins ornamentais e econômicos, acarretam uma série de prejuízos ao ecossistema natural e saúde humana. Segundo o Ministério do Meio Ambiente, a espécie exótica invasora, está em segundo lugar na perda de biodiversidade, sendo superada apenas pela destruição dos habitats (MMA, 2009).

Apesar disso, no Brasil é comum a introdução de espécies exóticas na arborização de praças públicas que muitas vezes predominam em número de espécies sobre as nativas, como observado em Guarapuava/PR (59,8\% de espécies exóticas), Maringá/PR (75,9\%) e Uberlândia/MG (63,73\%) (KRAMER; KRUPEK, 2012; BLUM; BORGO; SAMPAIO, 2008; REZENDE; SANTOS, 2010).

Todavia, a resolução desta problemática é obrigação dos órgãos públicos, que devem fiscalizar e interpor que seja efetivado um plano de manejo adequado no plantio de espécies adaptadas para cada região, tomando cuidado com as espécies exóticas para benefício da própria comunidade, além da flora e fauna local. Mesmo que plantas nativas quase não sejam utilizadas em arborização de praças, elas desempenham papéis importantes no equilíbrio ambiental. De acordo com Muneroli e Mascaró (2010), as plantas de ocorrência natural têm funções ecológicas, desde fornecer alimento e abrigo à fauna, até benefícios fornecidos ao meio ambiente e ao bem-estar da população. 


\section{Similaridade florística}

A similaridade florística entre as 12 praças foi baixa $(0,00$ a 0,25) (Figura 2). Apenas três grupos na análise de agrupamento apresentaram similaridade acima de 0,25: o primeiro grupo foi formado pelas praças PC1 e PC4 apresentou similaridade de 0,30; o segundo pelas praças PC5 e PC8 com similaridade de 0,28; e o terceiro pelas praças PC6 e PC7 com similaridade de 0,25.

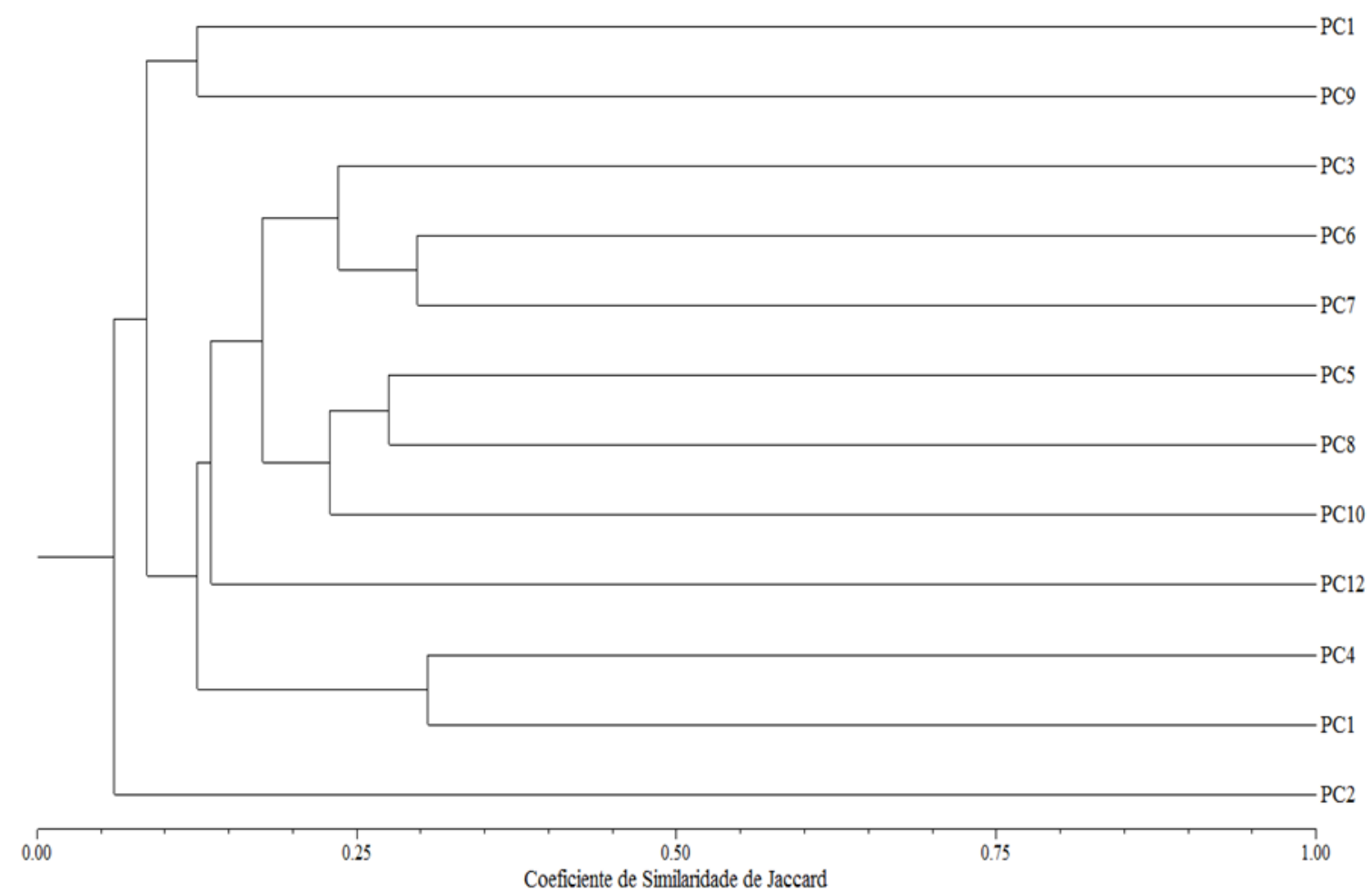

Nota: PC1 - Praça Aldenor Rodrigues Magalhães; PC2 - Suzinete Ferreira da Silva; PC3 - Luiza Pereira dos Santos; PC4 - Praça Padre José Mota; PC5 - Praça Dom Bosco; PC6 - Praça dos Pioneiros; PC7 - Praça Hermes Jefferson de Souza; PC8 - Praça Dona Rosa Ferreira Lima; PC9 - Praça José Mauricio Barroso; PC10 - Praça Raimundo Ricardo Alves; PC11 - Praça dos três Poderes; PC12 - Praça José Alencar Soares

Figura 2. Similaridade florística entre 12 praças localizadas em Nova Xavantina/MT, definida pelo método de UPGMA, com base no Coeficiente de Jaccard

Figure 2. Floristic similarity among 12 public squares located in Nova Xavantina/MT, defined by UPGMA method, based on Jaccard Coefficient

Embora a relação desses grupos tenha apresentado formação similar, no geral entre as áreas estudadas foi expressivamente baixo a similaridade (Figura 2), o que confirma a variedade de espécies entre as praças, registrando maior diversidade de espécies, não só de uma praça, mas no conjunto de todas as praças do município. Essa diversidade de espécies utilizadas na arborização das praças de Nova Xavantina pode ser reflexo de um bom planejamento, pois considerando o risco de pragas e doenças, que podem comprometer a 
longevidade das espécies, uma maior diversidade vegetacional equilibrada pode ser uma barreira a propagação e dominância dessas injurias (GREY; DENEKE, 1978).

As praças Aldenor Rodrigues Magalhães (PC1) e Padre José Mota (PC4) tiveram ocorrência comum das espécies Fabaceae 1 e Mangifera indica. As praças Dom Bosco (PC5) e Dona Rosa Ferreira Lima (PC8) apresentaram semelhança devido à presença das espécies Anacardium occidentale, Caesalpinia pluviosa, Handroanthus serratifolius, Hymenaea stignocarpa, Inga sp., M. indica, Pachira aquatica. Já entre as praças Hermes Jefferson de Souza (PC7) e dos Pioneiros (PC6), as espécies similares foram A. occidentale, Caryocar brasiliense, Calophyllum brasiliense, Dipteryx alata, $H$. stignocarpa, $H$. serratifolius, Jacaranda brasiliana, M. indica e Syagrus oleracea.

Foi possível notar pela análise de agrupamento, que entre as espécies de ocorrência nos três grupos formados, Mangifera indica apresentou predominância. Essa é uma espécie domesticada há milhares de anos e originária de locais de clima tropical e adaptada a ambientes com clima subtropical, apresentando plasticidade fenotípica, o que confere a ela facilidade de adaptação a diferentes ambientes, e atualmente está presente em todos os países de clima tropical e subtropical, sendo bem aceita pela população pelo fato da espécie possuir frutos comestíveis e apreciados pela maioria das pessoas, resultando assim em uma espécie de grande importância econômica e muito utilizada na arborização de praças no país (JOLY, 2002).

\section{CONCLUSÃO}

Nova Xavantina apresenta alta riqueza de espécies na arborização das praças do município, inclusive com a presença de espécies frutíferas em diversidade e densidade que proporciona equilíbrio entre fauna e flora local, além de algumas dessas espécies possuírem frutos apreciados pela população.

A maior porcentagem dessas espécies é nativa, fator positivo, pois proporciona o convívio das pessoas com características do bioma ao qual estão inseridas e mantem o equilíbrio ecológico, o que resulta em melhor qualidade ambiental.

O uso de plantas nativas na arborização é uma recomendação da Sociedade Brasileira de Arborização Urbana, portanto, em projetos futuros de arborização em Nova Xavantina, é indicado que continue a preferência por espécies nativas, haja vista que exóticas não foi predominante, mas se mantem consideravelmente presente na arborização municipal.

A baixa similaridade florística entre as praças, baixa densidade para cada espécie e a maior porcentagem de espécies nativas utilizadas na arborização dessas praças evidencia um bom planejamento de arborização, apresentando uma riqueza de espécie equilibrada. 


\section{REFERÊNCIAS}

AMARAL, E. V. E. J.; GUILHERME, F. A. G. Arborização em praças no município de Jataí, GO, Brasil. Revista da Sociedade Brasileira de Arborização Urbana, Piracicaba-SP, v. 9, n. 2, p. 18-33, 2014.

APG - ANGIOSPERM PHYLOGENY GROUP. BREMER, B.; BREMER, K.; CHASE, M. W.; FAY, M. F.; REVEAL, J. L.; SOLTIS, D. E.; SOLTIS, P. S.; STEVENS, P. F.; ANDERBERG, A. A.; MOORE, M. J.; OLMSTEAD, R. G.; RUDALL, P. J.; SYTSMA, K. J.; TANK, D. C.; WURDACK, K.; XIANG, J. Q. E.; ZMARZTY, S. An update of the Angiosperm Phylogeny Group classification for the orders and families of flowering plants: APG III. Botanical Journal of the Linnean Society, Londres, v. 161, n. 2, p. 105-121, 2009.

BLUM, C. T.; BORGO, M.; SAMPAIO, A. C. F. Espécies exóticas invasoras na arborização de vias públicas de Maringá-PR. Revista da Sociedade Brasileira de Arborização Urbana, Piracicaba-SP, v. 3, n. 2, p. 78-97, 2008.

CARVALHO, J. A.; NUCCI, J. C.; VALASKI, S. Inventário das Árvores Presentes na Arborização de Calçadas da Porção Central do Bairro Santa Felicidade. Revista da Sociedade Brasileira de Arborização Urbana, Piracicaba-SP, v. 5, n. 1, p. 126-143, 2010.

DANTAS, I. C.; SOUZA, C. M. C. Arborização urbana na cidade de Campina Grande - PB: Inventário e suas espécies. Revista de Biologia e Ciências da Terra, Campina Grande-PB, v. 4, n. 2, p. 1-18, 2004.

GREY, G. W.; DENEKE, F. J. Urban forestry. New York, John Wiley, 1978. 279p.

IBGE. Instituto Brasileiro de Geografia e Estatística. Censo demográfico de 2013. Disponível em: http://www.ibge.gov.br. Acesso em: 14 set. 2013.

JOLY, A. B. Botânica: Introdução à Taxonomia Vegetal. Ed.13. São Paulo: Companhia Editora Nacional, 2002. 424p.

KRAMER, J. A.; KRUPEK, R. A. Caracterização Florística e Ecológica da Arborização de Praça Públicas do Município de Guarapuava, PR. Revista Árvore, Viçosa-MG, v. 36, n. 4, p. 647-658, 2012.

MARIMON, B.S.; FELFILI, J.M.; LIMA, E.S.; DUARTE, W.M.G.; MARIMON-JUNIOR, B.H. Environmental determinants for natural regeneration of gallery forest at the Cerrado/Amazônia boundaries in Brazil. Acta Amazonica, Manaus-AM, v.40, p.107-118, 2010.

MARIMON-JUNIOR, B. H.; HARIDASAN, M. Comparação da vegetação arbórea e características edáficas de um cerradão e um cerrado sensu stricto em áreas adjacentes sobre solo distrófico no leste de Mato Grosso, Brasil. Acta Botanica Brasilica, São Paulo-SP, v. 19, n. 4, p. 913-926, 2005.

MELO, E. F. R. Q.; ROMANINI, A. Praça Ernesto Tochetto. Importância da sua Preservação Histórica e Aspecto de sua Arborização. Revista da Sociedade Brasileira de Arborização Urbana, Piracicaba-SP, v.3, n.1, p. 54-72, 2008.

MINISTÉRIO DO MEIO AMBIENTE; SECRETARIA DE BIODIVERSDADE E FLORESTA; COMISSÃO NACIONAL DE BIODIVERSIDADE. Estratégia Nacional sobre Espécies Exótica. 2009, 23p. 
MOURÃO, S. A.; KARAM. D.; SILVA, J. A. Uso de Leguminosas no Semiárido Mineiro. Sete Lagoas: Embrapa, 2011.91p.

MUELLER-DUMBOIS, P.; ELLENBERG, H. Aims and methods vegetation ecology. New York: Jonh Wiley e Sons, 1974. 547p.

MUNEROLI, C, C.; MASCARÓ, J, J. Arborização Urbana: Uso de Espécies Arbóreas Nativas na Captura do Carbono Atmosférico. Revista da Sociedade Brasileira de Arborização Urbana, Piracicaba-SP, v.5, n.1, p.160-182, 2010.

NETO, E. M. L.; RESENDE, W. X.; SENA, M. G. D.; SOUZA, R. M. Análise das Áreas Verdes das Praças do Bairro Centro e Principais Avenidas da Cidade de Aracaju, SE. Revista da Sociedade Brasileira de Arborização Urbana, Piracicaba-SP, v. 1, n. 1, p.17-33, 2007.

PESTANA, L. T. C.; ALVES, F. M.; SARTORI, A. L. B. Espécies arbóreas da Arborização Urbana do Centro do Município de Campo Grande, Mato Grosso do Sul, Brasil. Revista da Brasileira de Arborização Urbana, Piracicaba-SP, v. 6, n. 3, p. 01-21, 2011.

RADAMBRASIL. Levantamento de recursos naturais. Rio de Janeiro, Ministério das Minas e Energia 25, folha SD-22/Goiás. 1981.

REZENDE, T. M.; SANTOS, G. D. Avaliação Quali-Quantitaiva da Arborização das Praças do Bairro Jaraguá, Uberlândia. MG. Revista da Sociedade Brasileira de Arborização Urbana, Piracicaba-SP, v. 5, n. 2, p. 139-157, 2010.

SANTOS, E.; RAMALHO, R. S. O gênero Ficus (Moraceae) L. em Viçosa-MG. Revista Ceres, v. 44, n. 256, p. 646-665, 1997.

SANTOS, E. C.; SANTOS, C. Z. A.; GOMES, L. J. Função socioambiental de praças públicas de Aracaju-SE. Revista da Sociedade Brasileira de Arborização Urbana, Piracicaba-SP, v. 9, n. 2, p. 34-54, 2014.

SILVA, M. D. M.; SILVEIRA, R. R.; TEIXEIRA, M. I. J. G. Avaliação da arborização de vias públicas de uma área da região oeste da cidade de Franca/SP. Revista da Sociedade Brasileira de Arborização Urbana, Piracicaba-SP, v. 3, n. 1, p. 19-35, 2008.

SOUZA, A. L.; FERREIRA, R. A.; MELLO, A. A.; PLÁCIDO, D. R.; SANTOS, C. Z. A.; GRAÇA, D. A. S.; JÚNIOR, P. P. A.; BARRETTO, S. S. B.; DANTAS, J. D. M.; PAULA, J. W. A.; SILVA, T. L. S.; GOMES, L. P. S. Diagnóstico Quantitativo e Qualitativo da Arborização das Praças de Aracaju, SE. Revista Árvore, Viçosa-MG, v. 35, n. 6, p. 1253-1263, 2011.

VALE, N. F. L.; SOUSA, G. S.; MATA, M. F.; BRAGA, E. T. Inventário da Arborização do Parque da Cidade do Município de Sobral, Ceará. Revista da Sociedade Brasileira de Arborização Urbana, Piracicaba-SP, v. 6, n. 4, p. 145-157, 2011. 